\title{
鹖pubvet
}

https://doi.org/10.31533/pubvet.v16n02a1029.1-8

\section{Coronavírus canino: Revisão}

\author{
Júlia Soledade Marins Sobreira ${ }^{1 \oplus,}$, Alexandre de Pina $\operatorname{Costa}^{2} \oplus$ \\ ${ }^{I}$ Acadêmica de Medicina Veterinária Duque de Caxias, RJ, Brasil. \\ ${ }^{2}$ Médico Veterinário, Prof. Dr. Universidade do Grande Rio - Duque de Caxias, RJ, Brasil \\ *Autor para correspondência, E-mail: jsoledade@unigranrio.br
}

Resumo. A presente revisão teve como objetivo evidenciar o coronavírus que atinge os cães, visando recapitular a importância do mesmo em um período de pandemia. O coronavírus canino causa uma infecção altamente contagiosa com sinais clínicos caracterizados como gastroenterites leves a moderadas e respiratórios leves. Sua evolução depende de fatores imunes de cada indivíduo, podendo evoluir para o óbito. O diagnóstico geralmente é difícil, devido as manifestações clínicas que podem ser facilmente confundidos com os de outros patógenos, porém podem-se solicitar exames complementares, tais como observação em microscopia eletrônica, teste ELISA, RT-PCR e testes rápidos em clínicas veterinárias. O tratamento estabelecido é de suporte e variável de acordo com a clínica apresentada. A profilaxia deve ser orientada e inclui vacinação, ingestão de colostro materno, controle ambiental com higienização adequada e isolamento de animais infectados.

Palavras-chave: $\mathrm{CCoV}, \mathrm{CRCoV}$, Coronaviridae, enterite em cães

\section{Canine coronavirus: Review}

Abstract. This review aimed to highlight the coronavirus that affects dogs, aiming to recapitulate its importance in a period of pandemic. Canine coronavirus causes a highly contagious infection with signs and symptoms characterized as mild to moderate and mild respiratory gastroenteritis. Its evolution depends on each individual's immune factors, which may evolve to death. Diagnosis is usually difficult, symptoms that can be easily confused with those of other pathogens, but additional tests may be requested, such as observation in electron microscopy (EM), ELISA test, RT-PCR and rapid tests in veterinary clinics. The established treatment is supportive and varies according to the clinic presented. Prophylaxis must be guided and includes vaccination, ingestion of maternal colostrum, environmental control with adequate hygiene and isolation of infected animals.

Keywords: CCoV, CRCoV, Coronaviridae, enteritis in dogs

\section{Coronavirus canino: Revisión}

Resumen. Esta revisión tuvo como objetivo destacar el coronavirus que afecta a los perros, con el objetivo de recapitular su importancia en un período de pandemia. El coronavirus canino causa una infección altamente contagiosa con signos como gastroenteritis leves a moderadas y respiratorios leves. Su evolución depende de los factores inmunitarios de cada individuo, que pueden evolucionar hasta la muerte. El diagnóstico suele ser difícil debido a manifestaciones que pueden confundirse fácilmente con los de otros patógenos, pero se pueden solicitar pruebas adicionales, como observación en microscopía electrónica (EM), prueba ELISA, RT-PCR y pruebas rápidas en clínicas veterinarias. El tratamiento establecido es de apoyo y varía según la clínica presentada. La profilaxis debe ser guiada e incluye vacunación, ingestión de calostro materno, control ambiental con higiene adecuada $\mathrm{y}$ aislamiento de los animales infectados.

Palabras clave: $\mathrm{CCoV}, \mathrm{CRCoV}$, Coronaviridae, enteritis en perros 


\section{Introdução}

Relatados pela primeira vez em 1971 na Alemanha no decorrer de um surto epizoótico em fezes de cães filhotes com doença entérica aguda, os coronavírus são vírus envelopados de RNA+ que provocam doenças respiratórias, entéricas ou sistêmicas em diversos hospedeiros mamíferos tendo variedade em sua virulência de clínica, subclínica ou até fatal. A frequência de mutação e recombinação viral possui índices relativamente elevados possibilitando assim a sua adaptação a novos hospedeiros e nichos ecológicos (Barbosa et al., 2019; Binn et al., 1974; Flores, 2012; Haake et al., 2020).

No cão, o vírus se manifesta como coronavírus entérico canino (CECoV) que se refere a um patógeno comum em cães, tendo sua manifestação definida por enterite leve. Entretanto, surtos ocorrem de forma eventual, com maior frequência de sinais clínicos como enterite hemorrágica e fatal foram relacionados ao CECoV (Buonavoglia et al., 2006).

A susceptibilidade à infecção do coronavírus canino $(\mathrm{CCoV})$ é comum em populações caninas de todo o mundo, não se diferenciando entre raças e idades, conquanto a sensibilidade e desenvolvimento dos sinais clínicos de enterite são mais abrangentes em filhotes, e consequentemente maiores índices de mortalidade. A manifestação da doença ocorre de forma periódica em canis, abrigos e locais onde há convívio entre os cães (Flores, 2012; Navarro et al., 2017). Recentemente, a pandemia de COVID-19 (Sars-cov2) aumentou a relevância do estudo primordial sobre o coronavírus (CoVs) e também de forma crucial sobre a síndrome respiratória aguda grave CoV tipo 2 (SARS-CoV-2) (Wensman \& Stokstad, 2020).

O objetivo deste trabalho foi realizar uma revisão de literatura sobre a abrangência do coronavírus em cães, visto que recentemente houve uma amplificação no interesse por essa família, em virtude da classificação de um novo coronavírus humano o COVID-19.

\section{Etiologia}

Tendo como Ordem Nidovirales, a família coronaviridae tem o seu genoma estruturado por uma fita simples de RNA de sentido positivo com 27-30 kb de comprimento, envelopado de formato helicoidal, genoma portando 30,000 nucleotídeos de comprimento. Seu diâmetro pode variar de 80 a $160 \mathrm{~nm}$ com projeções superficiais observadas na microscopia eletrônica em forma de clava compreendendo de 12 a $24 \mathrm{~nm}$ assemelhando se a uma coroa (corona em latim) dando origem ao seu nome. Usualmente codifica as seguintes proteínas estruturais: $\mathrm{S}$ (espícula), hemaglutinina-esterase (HE), M (matriz) e $\mathrm{N}$ (nucleocapsídeo), conforme observado na Figura 1. Em sua classificação possui quatro grupos: Alphacoronavirus, Betacoronavirus, Gammacoronavirus e Deltacoronavirus (Gioti et al., 2021; Korsman et al., 2014).
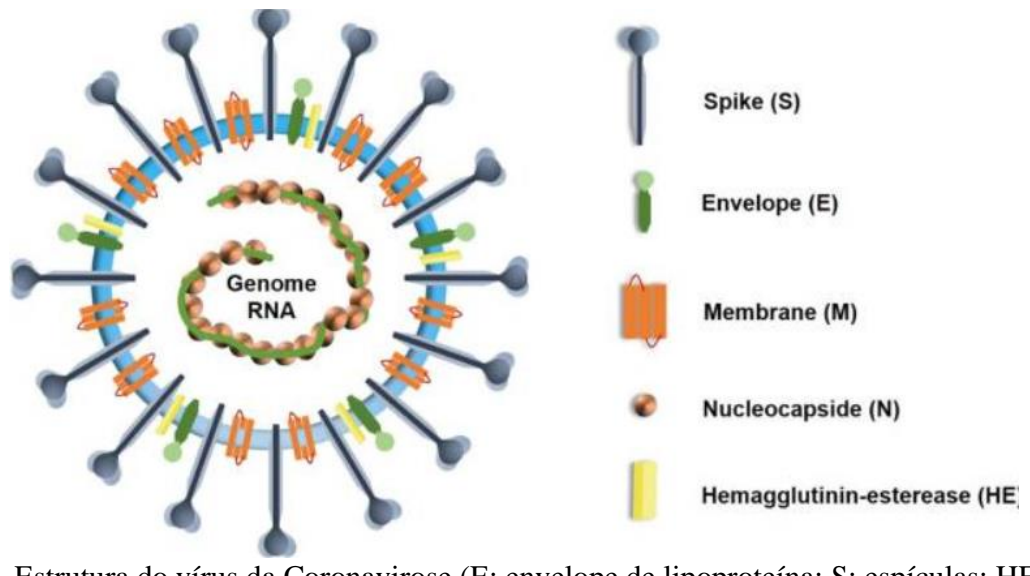

Figura 1. Estrutura do vírus da Coronavirose (E: envelope de lipoproteína; S: espículas; HE: hemaglutinina; L: proteína grande; M: proteína da matriz; N: nucleocapsídio). Fonte: Colina et al. (2021)

Pertence ao grupo I dos coronavírus e predispõe a recombinações em seu genoma. A região em que ocorre as principais recombinações são os genes da $\mathrm{M}$ e $\mathrm{S}$, possuindo propriedades biológicas e imunológicas relevantes. A glicoproteína $\mathrm{M}$ presente abaixo do envelope viral interage com o 
nucleocapsídeo e atua na morfogênese e brotamento dos vírions. Já a glicoproteína $S$, é encarregada pela ligação dos vírions aos receptores celulares, influencia a fusão do envelope com a membrana plasmática, possui sítios antigênicos que provocam a produção de anticorpos neutralizantes e induzem a resposta imune celular. A variedade na quantidade de cepas de referência se dá através das diferenças na sequência destes nucleotídeos (Flores, 2012). A proteína HE também presente no envelope viral, age como uma enzima destruidora de receptores funcionalmente interligada a glicoproteína S, portanto para uma fixação eficiente é necessário que a destruição do receptor e a ligação ao mesmo seja cautelosamente equilibrada (Lang et al., 2020). O nucleocapsídeo helicoidal abrange o genoma viral e seu capsídeo protetor, e as suas interações são fundamentais para a formação de partículas virais infecciosas (Fan et al., 2005; Vieira, 2019).

O mecanismo de replicação como observado na Figura 2, consiste na aptidão por recombinação homóloga e não homóloga, sendo estas relacionadas à habilidade de troca de fita do RdRp (RNA polimerase dependente de RNA), que supostamente se destaca na questão da evolução viral e também, é a base para a recombinação de RNA direcionada. Além da capacidade mutacional, em conjunto com a probabilidade de eventos de recombinação, potencialização de transmissão entre as espécies e capacidade de elevação do potencial zoonótico dos coronavírus e seus índices elevados em sua frequência de mutação e recombinação proporcionam a adaptação a novos hospedeiros e nichos ecológicos (Barbosa et al., 2019; Colina et al., 2021; Wang et al., 2020).

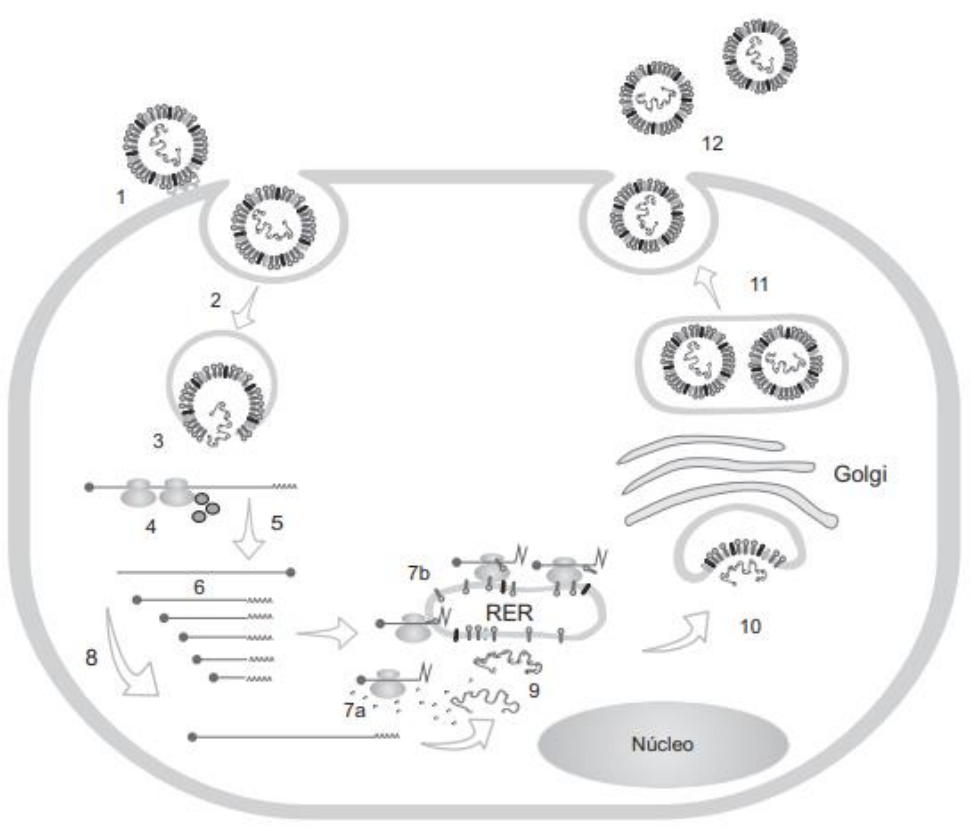

Figura 2. Demonstração simplificada da replicação dos coronavírus. 1) Ligação aos receptores celulares; 2) Internalização por endocitose (não acorrem em todos); 3) Penetração por fusão do envelope com a membrana endocítica; 4) Tradução da região 5' do genoma e produção da polimerase; 5) Síntese da cópia antigenômica; 6) Síntese dos mRNAs subgenômicos; 7a e 7b) Tradução dos mRNAs subgenômicos nas proteínas estruturais; 8) Síntese do RNA genômico; 9) Conjugação do RNA genômico com proteínas do nucleocapsídeo; 10) Brotamento do nucleocapsídeo no RER ou Golgi; 11) Transporte da progênie viral em vesículas até a membrana plasmática; 12) Egresso por exocitose. Fonte: Flores (2012).

\section{Patogenia e sinais clínicos}

Os cães são principalmente acometidos por três coronavírus que são eles: dois alfacoronavírus, o CCoV-I e CCoVII e um betacoronavírus CRCoV. Após a descoberta desses, uma recombinação através do vírus da gastroenterite transmissível de suínos e o CCoC-II induziu à diferenciação de dois subtipos, englobando o CCoV-IIa clássico e o CCoV-IIb recombinante (Bonilauri \& Rugna, 2021; Zobba et al., 2021). Em geral, as infecções causadas pelo CCoV, são reconhecidas por apresentar alta morbidade, porém baixa mortalidade. A via fecal-oral é de suma importância para a transmissão do coronavírus entérico canino por ser a principal fonte de contaminação, ou seja, após a ingestão o vírus infecta e se 
replica no citoplasma das células epiteliais das vilosidades intestinais, proporcionando o encurtamento e distorção do órgão, com redução do potencial de absorção do intestino delgado e como resultado um quadro de enterite. Além deste sintoma, também se observam sinais clínicos como gastroenterite leve a moderada, diminuição do apetite ou anorexia, êmese, diarreia fluida e consequentemente desidratação. Caso ocorra uma coinfecção com outros vírus, como por exemplo o Parvovírus canino, que consequentemente causa diarreia (pastosa e mucoide a líquida e hemorrágica), letargia, inapetência, êmese o caso pode se tornar fatal (Colina et al., 2021; Mazzaferro, 2020; Vieira, 2019).

A cepa CCoV-IIa hpervirulenta citada anteriormente, é conhecida como CCoV pantótipo (pCCoV), diagnosticada na Itália em 2005, possui a capacidade de dispersão para tecidos extra-intestinais. Por isso, a variante foi descrita como uma enfermidade multissistêmica fatal em cães, com sinais clínicos definidos por leucopenia, gastroenterite, letargia, inapetência, êmese diarreia hemorrágica, ataxia, convulsões e lesões avançadas nos principais órgãos, impactando na resposta imune canina (Alfano et al., 2020; Zobba et al., 2021). Já o betacoronavírus CRCoV provoca sinais clínicos respiratórios leves, por alterar a depuração mucociliar nas vias aéreas superiores (Zappulli et al., 2020). Este é apontado como agente etiológico da doença respiratória infecciosa canina a CIRD, e se encontra frequentemente associado a outros patógenos, tendo baixo potencial de causar infecções graves em caso de ser agente isolado. Em geral, acomete populações caninas que vivem aglomeradas, como por exemplo os abrigos (Bonilauri \& Rugna, 2021; Szczepanski et al., 2018).

Os sinais clínicos observados frequentemente, que podem ter início entre o primeiro e quarto dia após a infecção, incluem secreção nasal, dispneia, febre, prostração e infecções do trato respiratório inferior. Por serem semelhantes aos da CIRD, o diagnóstico diferencial acaba se tornando um grande desafio para os pesquisadores (Flores, 2012; Maboni et al., 2019). Segundo Wei et al. (2020), seus estudos demonstraram que o CRCoV em sua grande maioria se aloja pelo menos 1,5 vezes a mais nos pulmões do que nos intestinos, porém este pode possuir um potencial para tropismo duplo, devido ao fato de ter sido detectado no baço, linfonodos mesentéricos e cólon (Zappulli et al., 2020).

\section{Diagnóstico}

A enterite causada pelo Coronavírus canino possui um difícil diagnóstico devido à baixa gravidade de seus sinais clínicos comparados a outros tipos de enterite e por ser autolimitada. As principais células afetadas por ele e utilizadas para isolamento são as linhas de células CRFK, A-72 e cultivos de rim, timo e líquido sinovial, provocando mudanças detectáveis na célula hospedeira em função da infecção, como por exemplo a formação de sincícios. Deste modo, para a sua detecção é necessário o estudo exclusivo de fatores moleculares, etiológicos e sorológicos (Chen et al., 2019; Flores, 2012; Hao et al., 2021; Yoon et al., 2018).

A microscopia eletrônica abrange diversas técnicas que são capazes de compreender um amplo grupo de escalas, tecidos e macromoléculas, visualizado na Figura 3. Sendo assim, a ME pode ser uma prática comum para o diagnóstico laboratorial, através da utilização de fezes frescas (Flores, 2012; Wolff \& Bárcena, 2021).

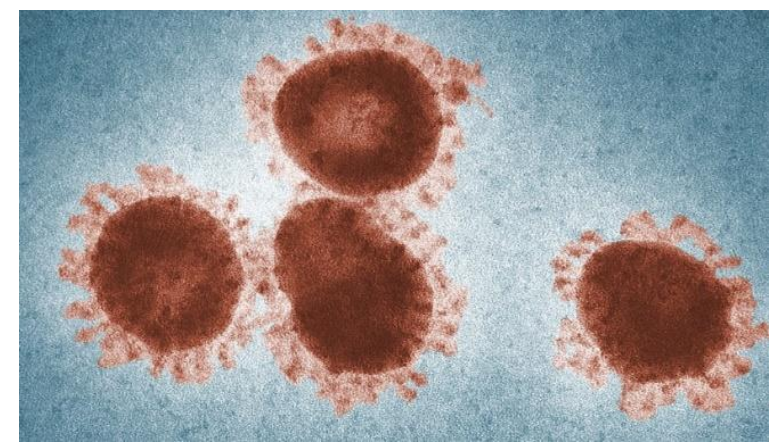

Figura 3. Coronavírus observado através da microscopia eletrônica. Fonte: FAPESP (2021)

Como diagnóstico tradicional e padrão ouro para a enterite coronaviral canina, pode ser utilizada a reação em cadeia da polimerase (PCR), que modernizou a pesquisa biológica e genética e consiste em um método automatizado estabelecido para amplificar nucleotídeos de interesse. Para a sua realização 
é necessário um conjunto de reagentes que amplificam a especificidade do PCR, tendo como consequência a eliminação e inibição da contaminação cruzada, diminuição do tempo de reação e aumento da capacidade de multiplexação. Entretanto, são inadequados para clínicas de pequenos animais devido aos complicados processos experimentais envolvidos e a necessidade de profissionais especializados (Fujita et al., 2018; Yoon et al., 2018; Zhu et al., 2020).

Com a necessidade de determinar técnicas que possibilitem a realização de medidas de controle eficazes para diagnóstico instantâneo e precoce, a fim de diminuir os danos, usa-se o kit para teste rápido (Figura 3). Este apresenta uma boa interpretação diagnóstica em clínicas veterinárias, além de resultados similares aos da PCR, provando assim ser apto para o uso adequado e preciso da rotina clínica (Wang et al., 2018; Yoon et al., 2018).

Segundo Hao et al. (2021), o método conhecido como imunofluorescência indireta e ensaio imunoenzimático (ELISA) demonstrou-se adequado tanto em relação a sensibilidade quanto a especificidade para identificação de anticorpos contra o $\mathrm{CCoV}$, sendo capaz de desempenhar o papel de um recente e eficaz ensaio diagnóstico. Em contrapartida, essa técnica consiste na neutralização do soro que é um método tradicional de detecção sorológica bem complexo e duradouro. Além do mais, tal método necessita de um laboratório equipado com alto nível de biossegurança para ser executado, sendo assim dificilmente utiliza-se a neutralização do soro para a detecção imediata em clínicas.

\section{Procedimento}
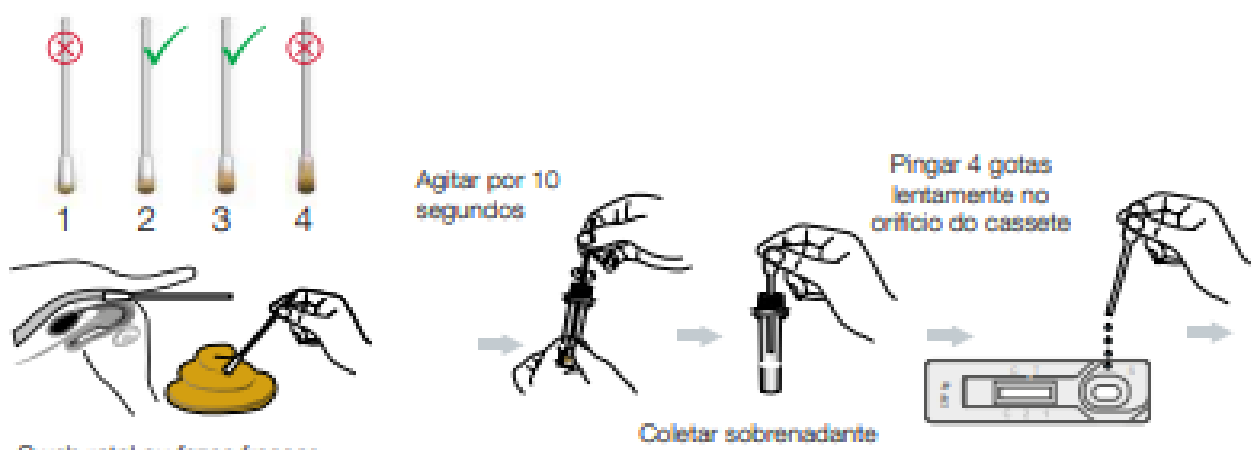

Interpretar o resultado de 5 a 10 minutbes

Swab retal ou fezes frescas

Coletar sobrenadante

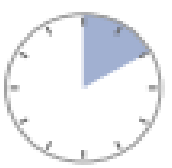

\section{Interpretação}

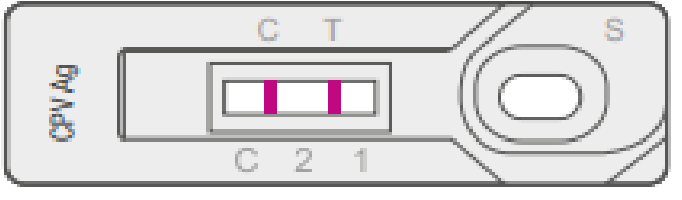

Resultado reagente

Duss linhas coradas ( $\mathrm{C}$ e $\mathrm{T}$ )

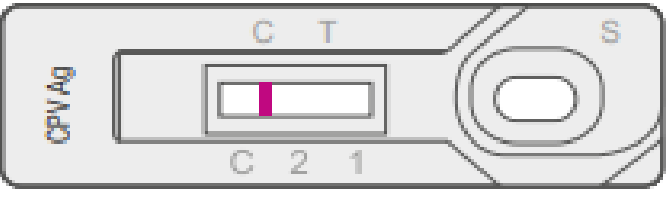

\section{Resultado não reagente} Somente a linha $(\mathrm{C})$ corada

Figura 4. Método de detecção simultânea para Parvovirose e Coronavirose canina em clínicas veterinárias, realizado através de amostras de fezes frescas ou swab retal e interpretação dos resultados. Fonte: Alere (2019).

\section{Tratamento e profilaxia}

O tratamento utilizado para a infecção causada pelo $\mathrm{CCoV}$ é apenas de suporte e inclui evitar eventuais infecções secundarias e a manutenção do equilíbrio hidroeletrolítico. Já a prevenção contra a infecção consiste em melhorias na higiene, quarentenas e diminuição das aglomerações, não realização do desmame de forma imatura (Dezengrini et al., 2007; Hass et al., 2008; Strottmann et al., 2008). Além disso, os estudos de Luo et al. (2020) relataram que é permitido fazer o uso de protocolos antivirais específicos, como por exemplo vacinas e Anticorpos monoclonais (mAbs), que são moléculas idênticas de imunoglobulinas, produzidas por clones individuais de células B elaboradas para um antígeno específico. 
Na natureza, a inativação do vírus acontece através do calor ou por solventes lipídicos, formaldeído, detergentes não iônicos e agentes oxidantes, apesar disso baixas temperaturas são capazes de manter a sua capacidade de infecção de forma duradoura (Dezengrini et al., 2007; Korsman et al., 2014; Strottmann et al., 2008).

Segundo Colina et al. (2021), mesmo com a existência de diversos imunizantes para a proteção do $\mathrm{CCoV}$, sua aplicação é questionável. Devido as vacinações serem comumente administradas no intervalo entre a oitava e décima segunda semana de idade e as infecções por CCoV correrem em cães com idade inferior a 6 semanas, estas se mostraram tardias para ocasionar efeito na prevenção da enfermidade.

Os imunizantes fabricados com o vírus atenuado foram testados e certificaram bons resultados, na qual cães vacinados pela via oral demonstraram títulos mais elevados da imunoglobulina $\mathrm{A}(\operatorname{IgA})$ e não expeliram o vírus nas fezes, enquanto aqueles que foram vacinados pela via intramuscular apresentaram títulos menores de IgA e eliminaram o vírus nas fezes durante 10 dias (Dezengrini et al., 2007; Korsman et al., 2014; Strottmann et al., 2008).

No mercado existem a disposição vacinas que protegem os cães contra a patologia causada pelo $\mathrm{CCoV}$; porém, não surte o mesmo efeito quando o canino se encontra infectado, visto que estudos evidenciam que a cepa pantótipa (pCCoV), que está associada a infecções subclínicas e/ou a redução da contagem de linfócitos, pode causar o falecimento do canino ao invés de graves sinais clínicos (Decaro et al., 2011; Zobba et al., 2021).

\section{Considerações finais}

Visto que o coronavírus canino é uma doença altamente contagiosa, autolimitada e raramente diagnosticada devido a sua gravidade ser menor comparada a outras enterites, quando não associada a outros patógenos, deve-se atentar para a questão da profilaxia, visando um protocolo instituído de forma apropriada para o canino em questão.

No entanto, a única relação existente entre o Coronavírus canino e o COVID-19 é a família à qual eles pertencem. As informações disponíveis sugerem que o risco de propagação zoonótica é baixo, com isso, faz-se necessário novas pesquisas para a confirmação deste tipo de transmissão, ainda assim é necessário cautela e comunicação eficaz com os tutores a fim de educá-los para evitar preconceitos desnecessários e abandonos.

Uma avaliação clínica das condições gerais do paciente deve ser efetuada a fim de dificultar possibilidades de contato e/ou transmissão para animais livres da enfermidade, visto que é de baixa complexidade. Em caso de suspeita clínica, métodos diagnósticos adequados devem ser requisitados, porém devido à alta dificuldade de diagnosticar o vírus, o tratamento deve ser efetuado para fornecer o suporte necessário para estabilizar o quadro clínico do canino infectado.

\section{Referências bibliográficas}

Alere (2019). Testes rápidos. Doenças infecciosas em cães e gatos. Diagnóstico Veterinário, 16p. https://vetsmartparsefiles.s3.amazonaws.com/7ad1a1e2e829bfb43a87f3bd4a580c5d_vetsmart_admin_pdf_file.pdf

Alfano, F., Fusco, G., Mari, V., Occhiogrosso, L., Miletti, G., Brunetti, R., Galiero, G., Desario, C., Cirilli, M., \& Decaro, N. (2020). Circulation of pantropic canine coronavirus in autochthonous and imported dogs, Italy. Transboundary and Emerging Diseases, 67(5), 1991-1999. https://doi.org/10.1111/tbed.13542.

Barbosa, C. M., Durigon, E. L., Thomazelli, L. M., Ometto, T., Marcatti, R., Nardi, M. S., Aguiar, D. M., Pinho, J. B., Petry, M. V., \& Simão Neto, I. (2019). Divergent coronaviruses detected in wild birds in Brazil, including a central park in São Paulo. Brazilian Journal of Microbiology, 50(2), $547-$ 556. https://doi.org/10.1007/s42770-019-00065-7.

Binn, L. N., Lazar, E. C., Keenan, K. P., Huxsoll, D. L., Marchwicki, R. H., \& Strano, A. J. (1974). Recovery and characterization of a coronavirus from military dogs with diarrhea. Proceedings, Annual Meeting of the United States Animal Health Association, 78, 359-366. 
Bonilauri, P., \& Rugna, G. (2021). Animal Coronaviruses and SARS-COV-2 in animals, what do we actually know? Life, 11(2), 123. https://doi.org/10.3390/life11020123.

Buonavoglia, C., Decaro, N., Martella, V., Elia, G., Campolo, M., Desario, C., Castagnaro, M., \& Tempesta, M. (2006). Canine coronavirus highly pathogenic for dogs. Emerging Infectious Diseases, 12(3), 492. https://doi.org/10.3201/eid1203.050839.

Chen, S., Liu, D., Tian, J., Kang, H., Guo, D., Jiang, Q., Liu, J., Li, Z., Hu, X., \& Qu, L. (2019). Molecular characterization of HLJ-073, a recombinant canine coronavirus strain from China with an ORF3abc deletion. Archives of Virology, 164(8), 2159-2164. https://doi.org/10.1007/s00705-01904296-9.

Colina, S. E., Serena, M. S., Echeverría, M. G., \& Metz, G. E. (2021). Clinical and molecular aspects of veterinary coronaviruses. Virus Research, 198382. https://doi.org/10.1016/j.virusres.2021.198382.

Decaro, N., Mari, V., Sciarretta, R., Colao, V., Losurdo, M., Catella, C., Elia, G., Martella, V., Del Giudice, G., \& Buonavoglia, C. (2011). Immunogenicity and protective efficacy in dogs of an MF59 ${ }^{\mathrm{TM}}$-adjuvanted vaccine against recombinant canine/porcine coronavirus. Vaccine, 29(11), 2018-2023. https://doi.org/10.1016/j.vaccine.2011.01.028.

Dezengrini, R., Weiblen, R., \& Flores, E. F. (2007). Soroprevalência das infecções por parvovírus, adenovírus, coronavírus canino e pelo vírus da cinomose em cães de Santa Maria, Rio Grande do Sul, Brasil. Ciência Rural, 37(1), 183-189.

Fan, H., Ooi, A., Tan, Y. W., Wang, S., Fang, S., Liu, D. X., \& Lescar, J. (2005). The nucleocapsid protein of coronavirus infectious bronchitis virus: crystal structure of its $\mathrm{N}$-terminal domain and multimerization properties. Structure, 13(12), 1859-1868. https://doi.org/10.1016/j.str.2005.08.021.

Fioravanti, C. (2020). Novo coronavírus no Brasil. Fapesp.br. Retrieved February 23, 2022, de https://revistapesquisa.fapesp.br/novo-coronavirus-no-brasil/

Flores, E. F. (2012). Virologia veterinária. Universidade Federal de Santa Maria.

Fujita, T., Yuno, M., Kitaura, F., \& Fujii, H. (2018). A refined two-step oligoribonucleotide interferencePCR method for precise discrimination of nucleotide differences. Scientific Reports, 8(1), 1-16. https://doi.org/10.1038/s41598-018-35479-0.

Gioti, K., Kottaridi, C., Voyiatzaki, C., Chaniotis, D., Rampias, T., \& Beloukas, A. (2021). Animal coronaviruses induced apoptosis. Life, 11(3), 185. https://doi.org/10.3390/life11030185.

Haake, C., Cook, S., Pusterla, N., \& Murphy, B. (2020). Coronavirus infections in companion animals: virology, epidemiology, clinical and pathologic features. Viruses, 12(9), 1023. https://doi.org/10.3390/v12091023.

Hao, Y.-F., Li, S.-H., Zhang, G.-Z., Xu, Y., Long, G., Lu, X., Cui, S.-J., \& Qin, T. (2021). Establishment of an indirect ELISA-based method involving the use of a multiepitope recombinant $S$ protein to detect antibodies against canine coronavirus. Archives of Virology, 166(7), 1877-1883. https://doi.org/10.1007/s00705-021-05072-4.

Hass, R., Johann, J. M., Caetano, C. F., Fischer, G., Vargas, G. D., Vidor, T., \& Hübner, S. O. (2008). Níveis de anticorpos contra o vírus da cinomose canina e o parvovírus canino em cães não vacinados e vacinados. Arquivo Brasileiro de Medicina Veterinária e Zootecnia, 60(1), 270-274.

Korsman, S. N. J., Van Zyl, G., Nutt, L., Andersson, M. I., \& Preiser, W. (2014). Virologia. Elsevier Brasil.

Lang, Y., Li, W., Li, Z., Koerhuis, D., Van Den Burg, A. C. S., Rozemuller, E., Bosch, B.-J., Van Kuppeveld, F. J. M., Boons, G.-J., \& Huizinga, E. G. (2020). Coronavirus hemagglutinin-esterase and spike proteins coevolve for functional balance and optimal virion avidity. Proceedings of the National Academy of Sciences, 117(41), 25759-25770. https://doi.org/10.1073/pnas.2006299117.

Luo, X., Zhou, G.-Z., Zhang, Y., Peng, L.-H., Zou, L.-P., \& Yang, Y.-S. (2020). Coronaviruses and gastrointestinal diseases. Military Medical Research, 7(1), 1-6. https://doi.org/10.1186/s40779-02000279-z.

Maboni, G., Seguel, M., Lorton, A., Berghaus, R., \& Sanchez, S. (2019). Canine infectious respiratory disease: new insights into the etiology and epidemiology of associated pathogens. PLoS One, 14(4), e0215817. https://doi.org/10.1371/journal.pone.0215817. 
Mazzaferro, E. M. (2020). Update on canine parvoviral enteritis. Veterinary Clinics: Small Animal Practice, 50(6), 1307-1325.

Navarro, R., Nair, R., Peda, A., Aung, M. S., Ashwinie, G. S., Gallagher, C. A., Malik, Y. S., Kobayashi, N., \& Ghosh, S. (2017). Molecular characterization of canine parvovirus and canine enteric coronavirus in diarrheic dogs on the island of St. Kitts: First report from the Caribbean region. Virus Research, 240, 154-160. https://doi.org/10.1016/j.virusres.2017.08.008.

Strottmann, D. M., Scortegagna, G., Kreutz, L. C., Barcellos, L. J. G., Frandoloso, R., \& Anziliero, D. (2008). Diagnóstico e estudo sorológico da infecção pelo parvovírus canino em cães de Passo Fundo, Rio Grande do Sul, Brazil. Ciência Rural, 38(2), 400-405.

Szczepanski, A., Owczarek, K., Milewska, A., Baster, Z., Rajfur, Z., Mitchell, J. A., \& Pyrc, K. (2018). Canine respiratory coronavirus employs caveolin-1-mediated pathway for internalization to HRT18G cells. Veterinary Research, 49(1), 1-14. https://doi.org/10.1186/s13567-018-0551-9.

Vieira, F. V. (2019). Coronavirus Canino: Aspectos bioenergéticos relacionados com a infecção in vitro de macrófagos caninos. Universidade Estadual Paulista (UNESP).

Wang, J., Luo, Y., Liang, L., Li, J., \& Cui, S. (2018). A fast and simple one-step duplex PCR assay for canine distemper virus (CDV) and canine coronavirus (CCoV) detection. Archives of VVrology, 163(12), 3345-3349. https://doi.org/10.1007/s00705-018-3982-8.

Wang, Y., Grunewald, M., \& Perlman, S. (2020). Coronaviruses: an updated overview of their replication and pathogenesis. Coronaviruses, 2203, 1-29. https://doi.org/10.1007/978-1-0716-0900$2 \_1$.

Wei, Y., Silke, J. R., Aris, P., \& Xia, X. (2020). Coronavirus genomes carry the signatures of their habitats. PLoS One, 15(12), e0244025. https://doi.org/10.1371/journal.pone.0244025.

Wensman, J. J., \& Stokstad, M. (2020). Could naturally occurring coronaviral diseases in animals serve as models for covid-19? A review focusing on the bovine model. Pathogens, 9(12), 991. https://doi.org/10.3390/pathogens9120991.

Wolff, G., \& Bárcena, M. (2021). Multiscale electron microscopy for the study of viral replication organelles. Viruses, 13(2), 197. https://doi.org/10.3390/v13020197.

Yoon, S.-J., Seo, K.-W., \& Song, K.-H. (2018). Clinical evaluation of a rapid diagnostic test kit for detection of canine coronavirus. Korean Journal of Veterinary Research, 58(1), 27-31. https://doi.org/10.14405/kjvr.2018.58.1.27.

Zappulli, V., Ferro, S., Bonsembiante, F., Brocca, G., Calore, A., Cavicchioli, L., Centelleghe, C., Corazzola, G., De Vreese, S., \& Gelain, M. E. (2020). Pathology of coronavirus infections: A review of lesions in animals in the one-health perspective. Animals, 10(12), 2377. https://doi.org/10.3390/ani10122377.

Zhu, H., Zhang, H., Xu, Y., Laššáková, S., Korabečná, M., \& Neužil, P. (2020). PCR past, present and future. BioTechniques, 69(4), 317-325. https://doi.org/10.2144/btn-2020-0057.

Zobba, R., Visco, S., Sotgiu, F., Parpaglia, M. L. P., Pittau, M., \& Alberti, A. (2021). Molecular survey of parvovirus, astrovirus, coronavirus, and calicivirus in symptomatic dogs. Veterinary Research Communications, 45(1), 31-40. https://doi.org/10.1007/s11259-020-09785-w.

\section{Histórico do artigo:}

Recebido: 3 de setembro de 2021 Aprovado: 30 de outubro de 2021 Disponível online: 18 de fevereiro de 2022
Licenciamento: Este artigoé publicado na modalidade Acesso Aberto sob a licença Creative Commons Atribuição 4.0 (CC-BY 4.0), a qual permite uso irrestrito, distribuição, reprodução em qualquer meio, desde que $\mathrm{o}$ autor $\mathrm{e}$ a fonte sejam devidamente creditados. 